\title{
Fabrication and Testing of All-solid-state Nanoscale Lithium Batteries Using LiPON for Electrolytes
}

\author{
Feihu Tan ${ }^{1}$, XiaoPing Liang ${ }^{1}$, Feng Wei ${ }^{1}$ and Jun $\mathrm{Du}^{2, *}$ \\ ${ }^{1}$ State Key Laboratory of Advanced Materials for Smart Sensing, General Research Institute for Nonferrous Metals, Beijing, China. \\ ${ }^{2}$ General Research Institute for Nonferrous Metals, Beijing, China.
}

\begin{abstract}
The amorphous LiPON thin film was obtained by using the crystalline $\mathrm{Li}_{3} \mathrm{PO}_{4}$ target and the $\mathrm{RF}$ magnetron sputtering method at a $\mathrm{N}_{2}$ working pressure of $1 \mathrm{~Pa}$. and then the morphology and composition of LiPON thin films are analysed by SEM and EDS. SEM shows that the film was compact and smooth, while EDS shows that the content of $\mathrm{N}$ in LiPON thin film was about $17.47 \%$. The electrochemical properties of $\mathrm{Pt} / \mathrm{LiPON} / \mathrm{Pt}$ were analysed by EIS, and the ionic conductivity of LiPON thin films was $3.8 \times 10^{-7} \mathrm{~S} / \mathrm{cm}$. By using the hard mask in the magnetron sputtering process, the all-solid-state thin film battery with $\mathrm{Si} / \mathrm{Ti} / \mathrm{Pt} / \mathrm{LiCoO}_{2} / \mathrm{LiPON} / \mathrm{Li}_{4} \mathrm{Ti}_{5} \mathrm{O}_{12} / \mathrm{Pt}$ structure was prepared, and its electrical properties were studied. As for this thin film battery, the open circuit voltage was $1.9 \mathrm{~V}$ and the first discharge specific capacity was $34.7 \mu \mathrm{Ah} / \mathrm{cm}^{2} \cdot \mu \mathrm{m}$ at a current density of $5 \mu \mathrm{A} / \mathrm{cm}^{-2}$, indicating that is promising in all-solidstate thin film batteries.
\end{abstract}

\section{Introduction}

Lithium ion battery is a common energy supply unit in the current equipment. With the development of miniaturization and integration of devices, all-solid-state thin film batteries have gradually attracted the attention of researchers. ${ }^{[1,2]}$ Compared with conventional lithium ionic batteries incorporating organic liquid electrolytes, all-solid-state thin film batteries are safer, lighter and more stable. ${ }^{[3,4]}$ The preparation process of all-solid-state batteries is beneficial to the integration of energy unit in electronic circuits. Moreover, with the development of wearable devices, especially in the fields of health monitoring and medical care, new requirements have also been put forward for energy units. All-solid-state thin film battery becomes an ideal energy supply units for wearable devices due to its advantages of safety and flexibility. ${ }^{[5-7]}$

For all-solid-state thin film batteries, the performance of solid electrolyte films significantly affects the power density, cycling stability, safety, high and low temperature characteristics and service life of the battery. A large number of studies have been carried out on solid electrolyte membranes. Various systems such as LLZO and LLTO was studied, ${ }^{[8,9]}$ in which the ionic conductivity of $50 \mathrm{Li}_{2} \mathrm{~S} \cdot 17 \mathrm{P}_{2} \mathrm{~S}_{5} \cdot 33 \mathrm{LiBH}_{4}$ and $\mathrm{Li}_{10} \mathrm{GeP}_{2} \mathrm{~S}_{12}$ system can even reach $10^{-3} \mathrm{~S} / \mathrm{cm},{ }^{[10,11]}$ but the comprehensive performance has prevented them from being applied at present. Among them, LiPON is a typical solid electrolyte, and its research history can be traced back to 1992. [12] Recently, RF magnetron sputtering, MOCVD, PLD and other methods have been adopted to prepare LiPON films with high ionic conductivity, ${ }^{[13-15]}$ the ionic conductivity of LiPON films prepared by magnetron sputtering is up to $\sim 10^{-6} \mathrm{~S} / \mathrm{cm}$, therefore, LiPON films were prepared by magnetron sputtering in this paper.

\section{Experimental}

Ti and Pt thin films were prepared on silicon substrates by RF magnetron sputtering, The Ti layer is designed to increase the binding force between $\mathrm{Pt}$ and silicon substrate. The chamber was evacuated first to a base pressure (below $3.5 \times 10^{-4} \mathrm{~Pa}$ ) using a turbo molecular pump and then nitrogen gas was fed into the chamber to a gas pressure of $1 \mathrm{~Pa}$. Then, LiPON thin film was deposited on $\mathrm{Si} / \mathrm{Ti} / \mathrm{Pt}$ from a 2 -inch $\mathrm{Li}_{3} \mathrm{PO}_{4}$ target $(99.9 \%$ purity), 30 min presputtering was performed before each deposition. The structure of the blocking electrode of $\mathrm{Pt} / \mathrm{LiPON} / \mathrm{Pt}$ was prepared to test the electrochemical properties of the LiPON electrolyte film. The thickness of $\mathrm{Pt}$ layer is about $100 \mathrm{~nm}$, and the reason for using $\mathrm{Pt}$ as a current collector is that Pt has good thermal stability and can reduce the mutual diffusion between $\mathrm{Pt}$ and LiPON.

All-solid-state thin film batteries fabricated by magnetron sputtering, it was composed of a thin filmed $\mathrm{LiCoO}_{2}$ positive electrode, a $\mathrm{Li}_{4} \mathrm{Ti}_{5} \mathrm{O}_{12}$ negative electrode, $\mathrm{Pt}$ is also used as a current collector. The electrolyte will completely cover the positive electrode during preparation to prevent the direct contact between positive and negative electrodes. Then we tested the charge and discharge performance of the thin film battery with $\mathrm{Si} / \mathrm{Ti} / \mathrm{Pt} / \mathrm{LiCoO}_{2} / \mathrm{LiPON} / \mathrm{Li}_{4} \mathrm{Ti}_{5} \mathrm{O}_{12} / \mathrm{Pt}$ structure.

\footnotetext{
* Corresponding author: dujun@grinm.com
} 
The cell size was $2 \mathrm{~mm} \times 2 \mathrm{~mm} \times 1.5 \mu \mathrm{m}$, and this is the so-called "Nano battery".

The crystal structures of $\mathrm{Li}_{3} \mathrm{PO}_{4}$ target and LiPON thin film was investigated by XRD measurement (MSAL-XD2). The microstructure and composition of LiPON thin film was analysed by SEM (Hitachi S4800), and the cross-sectional morphology of thin film cells is also analysed. Electrochemical impedance spectroscopy of $\mathrm{Pt} / \mathrm{LiPON} / \mathrm{Pt}$ was measured by electrochemical workstation (Princeton P4000). In addition, chargedischarge properties of this thin film cell were measured with a current of $0.1 \mathrm{C}$ by battery testing system (MACCOR-MC16).

\section{Results and discussion}

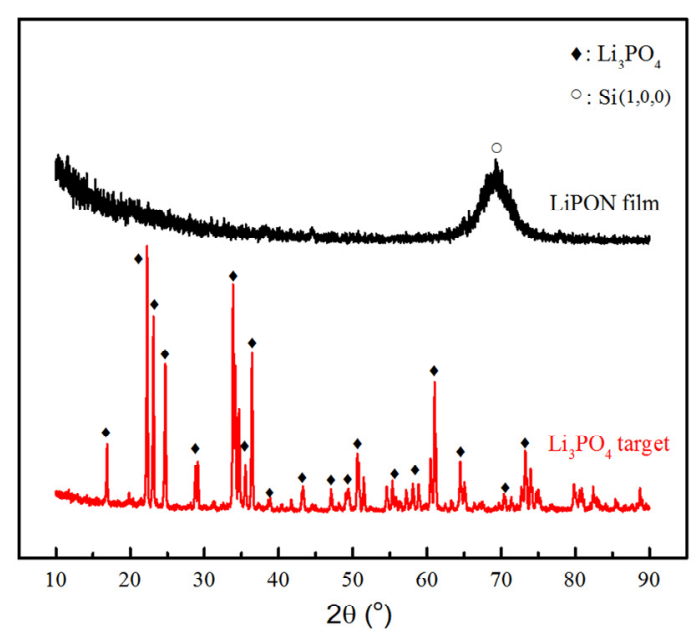

Fig. 1. XRD patterns of $\mathrm{Li}_{3} \mathrm{PO}_{4}$ target and the $\mathrm{LiPON}$ thin film on $\mathrm{Si}$ substrate.

Figure 1 shows the XRD patterns of $\mathrm{Li}_{3} \mathrm{PO}_{4}$ target and the LiPON thin film. The $\mathrm{Li}_{3} \mathrm{PO}_{4}$ target has a lot of sharp diffraction peaks, and these are due to the diffraction of crystalline $\mathrm{Li}_{3} \mathrm{PO}_{4}$, Indicating that the target material is pure and does not contain impurities. There is no diffraction peak in the diffraction pattern of LiPON thin film, except the Si peak, which indicates that the LiPON thin film is in an amorphous state. Moreover, according to various studies, the amorphous LiPON thin film has higher ionic conductivity than the crystalline state. ${ }^{[16]}$

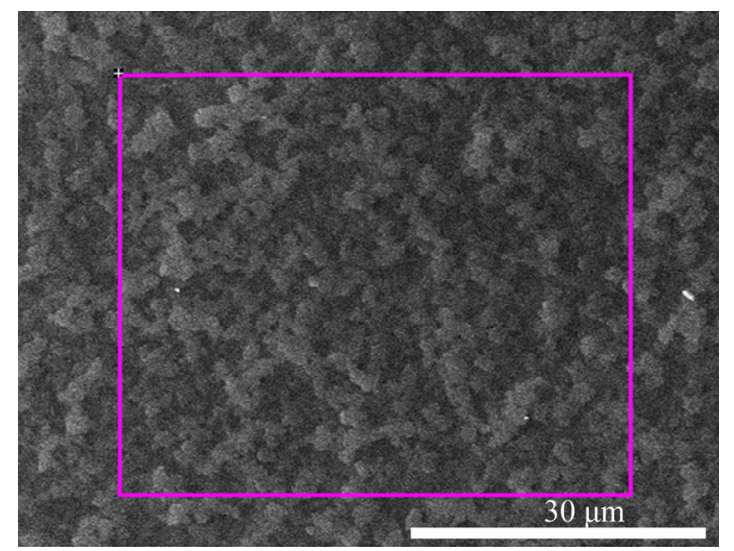

Fig. 2. The SEM image of LiPON thin film (marked as element analysis area).
Table 1. Component of LiPON thin film.

\begin{tabular}{|c|c|}
\hline Element & Atomic percent \\
\hline $\mathrm{N}$ & 17.47 \\
\hline $\mathrm{O}$ & 44.40 \\
\hline $\mathrm{P}$ & 17.11 \\
\hline others & 21.02 \\
\hline
\end{tabular}

Figure 2 shows the SEM image of LiPON film and its elemental analysis results. It can be seen that the prepared LiPON film is dense and without cracks. The solid thin film electrolyte needs to be dense so that the positive and negative electrodes can be separated to prevent short circuit and self-discharge. It is well known that the ionic conductivity of LiPON can be promoted by adding $\mathrm{N}$ elements, ${ }^{[17]}$ therefore, the content of each element in LiPON thin film was measured by EDS. The analysis area is the range of $40 \times 40 \mathrm{um}^{2}$ marked in the figure 2. The element composition is shown in table 1 , as is shown, the content of $\mathrm{N}$ elements in the LiPON thin film is about $17.47 \%$, indicating that $\mathrm{N}$ is successfully introduced in the process of deposition. And the ratio of $\mathrm{Li}$ is not correctly investigated yet, because the precise determination of atomic ratios in case of amorphous films, especially for a Li atom, is considerably difficult.

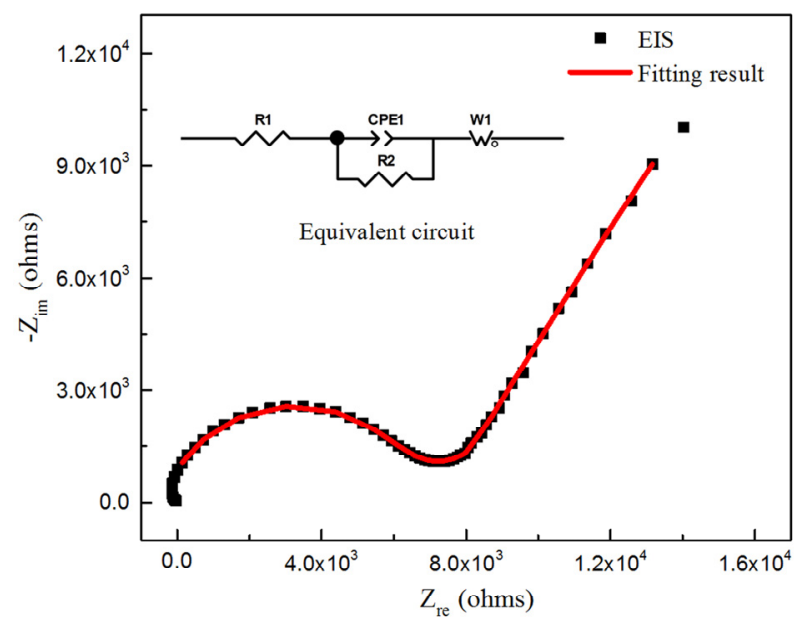

Fig. 3. Electrochemical impedance spectroscopy of the LiPON thin film, inset the equivalent circuits.

Figure 3 shows the AC electrochemical impedance spectroscopy of LiPON electrolyte thin film. Ionic conductivity is a very important parameter for thin film electrolyte. In general, ionic conductivity is calculated by the following formula:

$$
\delta=d /\left(R_{b} \cdot A\right)
$$

Where $\delta$ is the ionic conductivity and $\mathrm{d}$ is the thickness of the film, $R_{b}$ is the resistance of the film that is calculated from the measured impedance by selecting the value of $Z_{\text {re }}$ when $-Z_{\text {im }}$ goes through a local minimum in the electrochemical impedance spectra, and $A$ is the effective contact area of the electrode and electrolyte. ${ }^{[18]}$ 
Impedance spectroscopy was carried out to determine the ionic conductivity using a sandwich structure blocking electrode cell $(\mathrm{Pt} / \mathrm{LiPON} / \mathrm{Pt})$, the test frequency region from $1 \mathrm{~Hz}$ to $1 \mathrm{MHz}$. It can be seen from the figure that the $\mathrm{AC}$ impedance spectrum of LiPON thin films is constant by a semicircle with high frequency and a straight line set with low frequency. The semi-circle in the high frequency zone is mainly produced by the LiPON electrolyte, and the line in the low frequency zone is caused by the interface between the electrolyte and Pt electrode. The electrochemical impedance spectra of LiPON were fitted appropriately, and the equivalent circuit is presented in figure 3 . The ionic conductivity of LiPON thin film was calculated by Nyquist Diagram of $3.8 \times 10^{-7} \mathrm{~S} / \mathrm{cm}$.
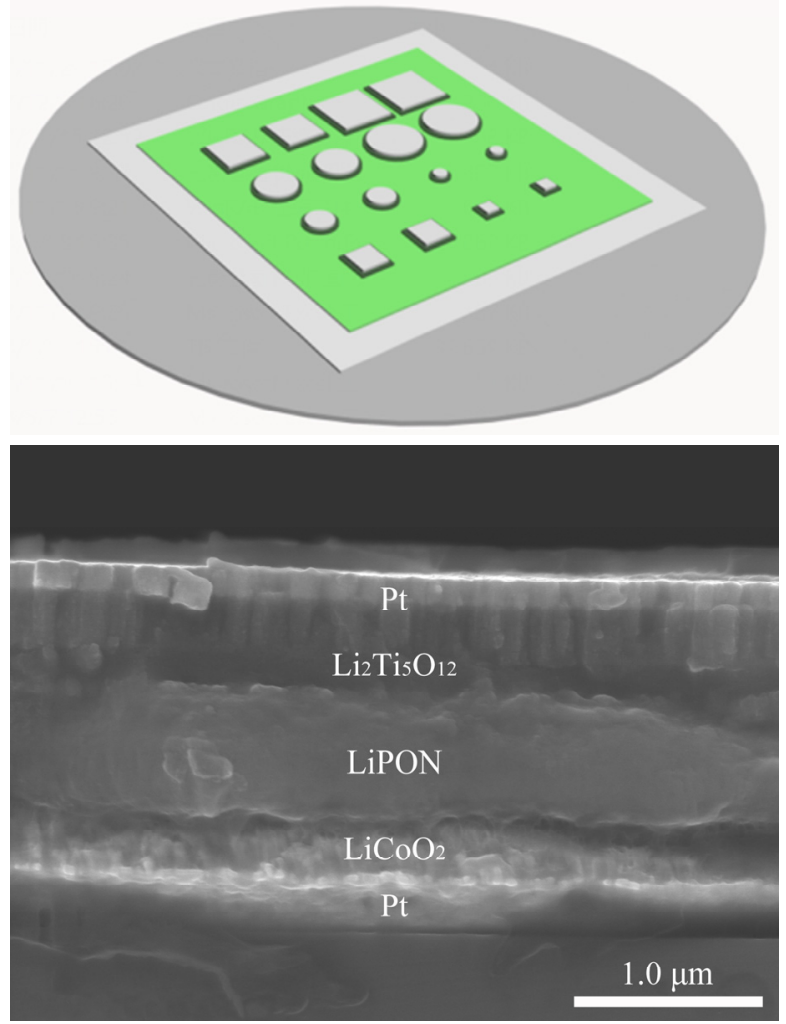

Fig. 4. (a) Schematic diagram of all-solid-state thin film battery, (b) Cross-sectional SEM image of all-solid-state thin film battery.

All-solid-state thin film battery is prepared by sequentially depositing a current collector, a positive electrode, an electrolyte, a negative electrode, and a current collector, the shapes of various films are controlled by the shape of the hard mask. The structure of the final thin film battery is shown in Figure 4(a). Figure 4(b) shows the cross-section SEM diagram of the thin film battery with $\mathrm{Si} / \mathrm{Ti} / \mathrm{Pt} / \mathrm{LiCoO}_{2} / \mathrm{LiPON} / \mathrm{Li}_{4} \mathrm{Ti}_{5} \mathrm{O}_{12} / \mathrm{Pt}$ structure. It can be seen that all the films exhibit a fully dense structure with no cracks, and the LiPON layer successfully separates $\mathrm{LiCoO}_{2}$ from $\mathrm{Li}_{4} \mathrm{Ti}_{5} \mathrm{O}_{12}$. The thickness of $\mathrm{LiCoO}_{2}$ film is about $280 \mathrm{~nm}$, and its growth morphology is in a typical column shape. No grains were observed in LiPON thin films, which was consistent with the result of XRD indicating that the films were amorphous.

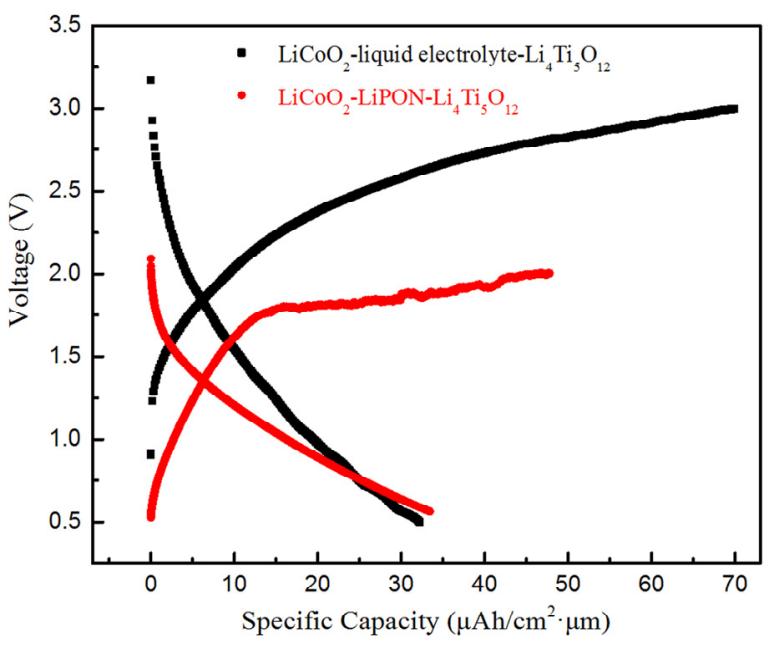

Fig. 5. Charge-discharge characteristics of the all solid state thin film battery and the contrast sample.

In order to investigate the performance of LiPON electrolyte thin films, all-solid-state thin film battery with $\mathrm{Si} / \mathrm{Ti} / \mathrm{Pt} / \mathrm{LiCoO}_{2} / \mathrm{LiPON} / \mathrm{Li}_{4} \mathrm{Ti}_{5} \mathrm{O}_{12} / \mathrm{Pt}$ structure was prepared and its performance was tested. The most widely used $\mathrm{LiCoO}_{2}$ is used as positive electrode. The $\mathrm{Li}_{4} \mathrm{Ti}_{5} \mathrm{O}_{12}$ of spinel structure is used as negative electrode because it has the advantage of zero strain when embedded with lithium ions (volume change rate is about $0.2 \%)^{[19]}$ Pt with good chemical stability and thermal stability is used as a current collector. The charge-discharge performance of thin film batteries with a $2 \mathrm{~mm} \times 2 \mathrm{~mm}$ size is shown in fingure 5, a thin film battery with $\mathrm{Al} / \mathrm{LiCoO}_{2} / \mathrm{Liquid}$ electrolyte $/ \mathrm{Li}_{4} \mathrm{Ti}_{5} \mathrm{O}_{12} / \mathrm{Al}$ structure is added for comparison.

As shown in figure 5, the charge voltage of all-solidstate battery starts from $0.5 \mathrm{~V}$, Charging platforms appear at $1.9 \mathrm{~V}$, thin film batteries using liquid electrolyte have significantly higher charging platforms and larger capacity. This is partly due to the resistance inside the LiPON thin film electrolyte itself and partly due to the impedance generated by the interface between the electrolyte layer and electrode layer. The voltage of thin film battery with liquld electrolyte decreases gradually from $3.2 \mathrm{~V}$ to $0.5 \mathrm{~V}$ at the current density of $0.1 \mathrm{C}$, and the voltage of all-solid-state thin film battery decreases gradually from $2.1 \mathrm{~V}$ to $0.6 \mathrm{~V}$, which indicates that LiPON thin film electrolyte has good lithium ion transmission performance. At the same time, the thin film battery prepared in this paper also showed good cycle characteristics. After 50 cycles of charge and discharge, the battery capacity has only a small amount of attenuation. The results show that the thin film battery is suitable for micro devices, in addition, thin film batteries are also beneficial to the production of flexible batteries, indicating that thin film batteries have good application prospects in micro devices and wearable devices.

\section{Conclusions}

LiPON electrolyte films with a thickness of $700 \mathrm{~nm}$ were prepared by RF magnetron sputtering, The structure of the blocking electrode of $\mathrm{Pt} / \mathrm{LiPON} / \mathrm{Pt}$ was prepared to 
test the electrochemical properties of the LiPON electrolyte film, and the ionic conductivity of LiPON films was calculated as $3.8 \times 10^{-7} \mathrm{~S} / \mathrm{cm}$. Through the combination of magnetron sputtering and hard mask, the all-solid-state thin film battery with $\mathrm{Si} / \mathrm{Ti} / \mathrm{Pt} / \mathrm{LiCoO}_{2} / \mathrm{LiPON} / \mathrm{Li}_{4} \mathrm{Ti}_{5} \mathrm{O}_{12} / \mathrm{Pt}$ structure was prepared, and the charge and discharge performance of the all solid state thin film battery was analyzed. The specific capacity density of the thin film battery is 34.7 $\mu \mathrm{Ah} / \mathrm{cm}^{2} \cdot \mu \mathrm{m}$.

\section{Acknowledgment}

This study was financially supported by International Science \& Technology Cooperation Program of China (Nos. 2015DFA00730) and Beijing Nova Program (Nos. Xx2016046).

\section{References}

1. T. Stephenson, Z. Li, B. Olsen, D. Mitlin, Energ. Environ. Sci. 7, 209 (2014)

2. D. Miranda, C.M. Costa, S. Lanceros-Mendez,. J. Electroanal. Chem. 739, 97 (2015)

3. J. Xie, J.F. Oudenhoven, P.P.R. Harks, D. Li, P.H. Notten, J. Electrochem. Soc. 162, A249 (2015)

4. Y. Li, W. Zhou, X. Chen, X. Lü, Z. Cui, S. Xin, J.B. Goodenough, P. Natl. Acad. Sci. 113, 13313 (2016)

5. Y. Meng, Y. Zhao, C. Hu, H. Cheng, Y. Hu, Z. Zhang, L. Qu, Adv. Mater. 25, 2326 (2013)

6. Z. Niu, L. Zhang, L. Liu, B. Zhu, H. Dong, X. Chen, Adv. Mater. 25, 4035 (2013)

7. X. Yang, F. Zhang, L. Zhang, T. Zhang, Y. Huang, Y. Chen, Adv. Funct. Mater. 23, 3353 (2013)

8. K.P. Abhilash, P.C. Selvin, B. Nalini, P. Nithyadharseni, B.C. Pillai, Ceram. Int. 39, 947 (2013)

9. T. Thompson, J. Wolfenstine, J.L. Allen, M. Johannes, A. Huq, I.N. David, J. Sakamoto, J. Mater. Chem. A, 2, 13431 (2014)

10. S. Wenzel, S. Randau, T. Leichtweiß, D.A. Weber, J. Sann, W.G. Zeier, J. Janek, Chem. Mater. 28, 2400 (2016)

11. A. Hayashi, H. Muramatsu, T. Ohtomo, S. Hama, M. Tatsumisago, J. Alloy. Compd. 591, 247 (2014)

12. Y. Hamon, A. Douard, F. Sabary, C. Marcel, P. Vinatier, B. Pecquenard, A. Levasseur, Solid State Ionics, 177, 257 (2006)

13. C.H. Choi, W.I. Cho, B.W. Cho, H.S. Kim, Y.S.Yoon, Y.S.Tak, Electrochem. Solid. ST, 5, A14 (2002).

14. L. Meda, E.E. Maxie, Thin solid films, 520, 1799 (2012)

15. W.C. West, Z.D. Hood, S.P. Adhikari, C. Liang, A. Lachgar, M. Motoyama, Y. Iriyama, J. Power Sources, 312, 116 (2016)
16. C. Lethien, M. Zegaoui, P. Roussel, P. Tilmant, N. Rolland, P.A. Rolland, Microelectron. Eng. 88, 3172 (2011)

17. B. Fleutot, B. Pecquenard, H. Martinez, A. Levasseur, Solid State Ionics, 206, 72 (2012)

18. S. Lorant, C. Bohnke, M. Roffat, O. Bohnke,. Electrochim. Acta, 80, 418 (2012)

19. A.S. Prakash, P. Manikandan, K. Ramesha, M. Sathiya, J.M. Tarascon, A.K. Shukla,. Chem. Mater. 22, 2857 (2010) 